Cad.Est.Ling., Campinas, 47(1) e (2):195-201, 2005

\title{
RECONTAGEM: SOBRE A NOVELA FAMILIAR FREUDIANA OU O MITO INDIVIDUAL LACANIANO *
}

\author{
RENATA MAZAFERRO ${ }^{1}$ \\ (Programa de Doutorado EM LingÜÍSTICA-UNICAMP)
}

\begin{abstract}
The article examines the preliminary ideas that will be part of my Master's dissertation. The aim of this dissertation is the study of the structure and function of childhood stories in the child's trajectory from the state of infans to that of subject-speaker. We have identified the children's story-telling act as a privileged place to board our question. The main focus of this article is on the theme of the myth and authors on Language Acquisition, Anthropology and Psychoanalysis are discussed.
\end{abstract}

\begin{abstract}
Abrimos esta exposição com o registro de Freud (1988 [1908]):
"Não devemos esquecer, entretanto, de examinar aquele outro tipo de obras imaginativas que não são uma criação original do autor, mas uma reformulação de material preexistente e conhecido ... Embora esse material não seja novo, procede do tesouro popular dos mitos, lendas e contos de fadas..., é muito provável que os mitos, por exemplo, sejam vestígios distorcidos de fantasias plenas de desejos de nações inteiras, os sonhos seculares da humanidade jovem” (op.cit, pág.157).
\end{abstract}

É interessante notarmos que Lacan (1992 [1970]), no seminário "O avesso da psicanálise", propôs que o complexo de Édipo fosse analisado como um sonho de Freud e que - como todo sonho - este requeria uma interpretação.

De Lemos (2002) assinalou:

“... as histórias infantis estão presentes na cultura de todos os povos e na interação mãe-criança das mais diversas comunidades. A meu ver, essa onipresença merece ser interrogada, ao mesmo título que os mitos o foram pela antropologia, do ponto de vista de sua estrutura e função - ou eficácia simbólica (cf. Lévi-Strauss 1955/1974, entre outros)” (op.cit, pág.7).

A entrada em nossa questão se faz pelo retorno às colocações de De Lemos, Freud e Lacan. Nossa proposta de dissertação de mestrado afina-se com a consideração de De

* Trabalho apresentado no Seminário Comemorativo dos 25 anos do Projeto de Aquisição de Linguagem do Instituto de Estudos da Linguagem (IEL), da Universidade Estadual de Campinas (UNICAMP); na mesaredonda: "Perspectivas emergentes: novos projetos de pesquisa e teses em andamento", em 23 de outubro de 2002.

${ }^{1}$ Doutoranda em Lingüística pelo IEL/ UnICAMP, sob orientação da Prof ${ }^{a}$ Dr ${ }^{a}$ Cláudia Thereza Guimarães de Lemos. O tema deste artigo está relacionado com a tese de mestrado da autora. Projeto apoiado financeiramente pela CAPES. E-mail: rmazaferro@ig.com.br. 
Lemos (2002), na medida em que propõe o estudo da estrutura e função das histórias infantis na constituição subjetiva da criança, no momento ímpar marcado por uma transição, a saber - de infans ${ }^{2}$ para sujeito falante.

O lembrete freudiano aponta a importância do exame de um tipo de obra imaginativa, a reformulação de material preexistente e conhecido, o qual foi encarado em distinção da criação original do autor. Segundo Freud, nesta reformulação há um empréstimo de material procedente do tesouro popular: os mitos, as lendas e os contos de fadas. Destacamos este aspecto para situar o material eleito para nossa investigação - a recontagem de histórias ${ }^{3}$ realizada pela criança - considerada por nós como uma espécie de reformulação, nos termos freudianos.

Na recontagem, a fala da criança deixa transparecer a inserção de elementos de sua própria história naqueles preexistentes e conhecidos como os do conto de fadas. Os elementos da história da criança que comparecem na recontagem não refletem exclusivamente ocorrências sincrônicas ao que se passa no tempo em que há a narração de determinada história/conto. Assim entendemos que, na recontagem, a fala da criança apresenta uma reformulação do material preexistente e conhecido do universo ficcional infantil, realizada pelo atravessamento de lembranças de seu dia-a-dia, promovendo composições singulares e insólitas.

Se Freud propõe os mitos como sonhos da humanidade, a proposta do "freudiano" Lacan é de que o complexo de Édipo seja pensado como um sonho de Freud, o inventor da Psicanálise. O termo Sonho $(s)$ deve ser tomado no sentido psicanalítico, como cifração do inconsciente, ciframento da ordem da letra, uma escrita; o sonho é a realização de desejo (inconsciente) - neste sentido dizemos que todo sonho requer uma interpretação.

Vale notar que o complexo de Édipo é um conceito central da teorização freudiana, é uma estrutura de relações entre certas posições (pai, mãe e filho/a), responsável pelo ingresso do sujeito na ordem simbólica; uma estrutura lingüística permanente que determina sentido à operação de constituição do sujeito pelo significante, de forma retroativa. Trata-se, portanto, de um conceito relevante em nosso estudo.

Nossa hipótese inicial acerca da estrutura e função das histórias infantis na constituição do sujeito falante inspira-se na seguinte afirmação de Ana Maria Medeiros da Costa (1998):

\footnotetext{
“Os contos infantis, por exemplo, povoam o imaginário infantil de elementos que vão auxiliar a criança na construção de uma forma de interpretar o real”" (op.cit., pág. 62).
}

Retomar De Lemos (op.cit) importa; segundo a pesquisadora, uma interrogação acerca da estrutura e função das histórias infantis minimamente afetaria hipóteses formuladas por

\footnotetext{
2 Trata-se da criança, no período anterior à chamada aquisição de linguagem.

${ }^{3}$ Histórias pertencentes ao tesouro popular, as quais a criança teve acesso por intermédio do Outro. O termo "Outro" será empregado na referência ao adulto interlocutor da criança, considerado como instância de funcionamento da língua.

${ }^{4}$ Destacamos que o termo "real" deve ser tomado no sentido da psicanálise, sinteticamente trata-se de um evento que resiste à representação e, portanto, não deve ser entendido como realidade.
} 
Cadernos de Estudos Lingüísticos 47(1) e (2) - Jan./Dez. 2005

distintas teorias, as quais concebem o chamado contexto físico imediato como o fornecedor de subsídio para que a criança - na fase inicial de aquisição - ingresse na língua(gem). A hipótese de que tais teorias sofreriam um abalo é sustentada pelo fato da investigadora reconhecer que as histórias infantis - estas contadas pelas mães desde cedo às suas crianças - absolutamente não tratam do "aqui-agora", nem mesmo de qualquer cotidiano suposto neste "aqui-agora". A investigadora admite uma relação, que considera inegável, entre as histórias ditas infantis e o mito coletivo.

Declarado que nosso interesse incide nesta relação, não poderíamos refletir sobre o mito senão incluindo, necessariamente, Lévi-Strauss (1995 [1958]) nesta discussão. Não nos passa desapercebido o quanto o antropólogo cita o lingüista, também nominalmente: Saussure "atravessa" o texto de Lévi-Strauss. Em linhas gerais, destacaremos algumas considerações do autor em "A estrutura dos mitos".

Lévi-Strauss (1995 [1958]) apontou para particularidades do mito: neste, não há uma regra de lógica que determine a sucessão de fatos, imprimindo uma continuidade; não há predicação de sujeito ou relação concebida de antemão - até aqui sua definição se faz pela negatividade. Nas palavras do autor, no mito: “tudo é possível” (op.cit, pág.231). É pontuado que, ainda assim, os mitos, em sua aparente arbitrariedade, se vêem reproduzidos - numa relação de identidade - quanto a seus caracteres e também em seus detalhes, no mundo afora.

Lévi-Strauss interroga-se, localizando um problema: se a contingência marca o mito em seu conteúdo, o que levaria a relação de identidade (minimamente parcial) entre eles em extremos da Terra? Lança a questão para, então, destacar algo que pertence à natureza do mito: sua antinomia fundamental, e determina que, só se conscientizando disto, é possível resolver tal antinomia.

Surge uma advertência explicitamente endereçada à lingüística:

\footnotetext{
“Aproximar o mito da linguagem não resolve nada: o mito integra a língua, pela fala se o conhece; pertence ao discurso” (Lévi-Strauss, op.cit:231)
}

no entanto, o antropólogo reconhece que a lingüística não está alheia a este apontamento. E afirma que:

"Se queremos dar conta dos caracteres específicos do pensamento mítico, teremos que estabelecer então que o mito está na linguagem e ao mesmo tempo mais além da linguagem” (Lévi-Strauss, op.cit:232).

A distinção de Saussure entre língua e fala é retomada por Lévi-Strauss, o qual considera que o que conta é o tempo aos quais se referem; a primeira pertencendo ao domínio de um tempo que comporta reversibilidade, enquanto que a segunda pertencendo a um tempo irreversível. Avança considerando que, se a linguagem pode ser segregada nestes dois níveis, não haveria impedimento na possibilidade de definição de um terceiro nível.

O autor promove esta discussão para definir o mito também através de um sistema temporal, no qual haveria uma combinação da propriedade dos outros dois - reversibilidade 
e irreversibilidade. Esta posição é sustentada pelo fato de que o mito faz (sempre) referência a acontecimentos passados; no entanto, estes acontecimentos supostamente já ocorridos num momento do tempo compõem uma estrutura permanente, a qual refere-se ao passado, ao presente e ao futuro - em simultaneidade - e é deste fato que podemos extrair o valor intrínseco atribuído ao mito.

A historicidade e a ahistoricidade constituem a estrutura do mito enquanto dupla, o que justifica que ele pode pertencer simultaneamente a ambos os domínios, ao da fala e ao da língua. A fala permite a análise do mito, enquanto que a língua permite sua formulação. Esta condição oferece, ao mesmo tempo, um terceiro nível que também é de natureza lingüística, embora distinto dos outros dois. Conforme Lévi-Strauss, é a história relatada que determina a substância do mito, não é o estilo, o modo de narração, nem a sintaxe.

Cabe recordarmos que um dos interesses de nossa dissertação é acerca disto: uma história relatada por uma criança singular. Aproveitamos para abrir um parêntese para Ítalo Calvino (1997); segundo o autor,

\begin{abstract}
"O mito é a parte escondida de toda história, a parte subterrânea, a zona ainda não explorada porque faltam ainda palavras para chegar até lá (...) é um vácuo de linguagem que aspira as palavras no seu turbilhão e dá forma à fabula. Mas o que é um vácuo de linguagem senão o traço de um tabu, de uma interdição de falar de alguma coisa, de pronunciar certas palavras; o traço de uma interdição atual ou antiga?" (op.cit, pág.77).
\end{abstract}

Podemos destacar, a partir disto, o mito como algo obscuro de uma história, e esta obscuridade como inerente a uma falta que remete, necessariamente, à questão da linguagem. É interessante a perspectiva de que a partir do que ele chama de um vácuo de linguagem, as palavras são aspiradas no seu turbilhão e que esta "aspiração"s dá forma a uma fábula ao contornar um vazio - ao delimitar o real?

Retomemos Lévi-Strauss que, a partir das considerações comentadas acima, afirmou:

"o mito requer uma organização em função de um sistema de referência temporal de um novo tipo, que satisfaça as exigências da hipótese inicial. Este sistema é, em efeito, de duas dimensões, diacrônico e sincrônico, com o qual se reúnem propriedades da língua e da fala” (op.cit, pág. 234).

Uma outra característica pertence ao mito, trata-se da repetição de seqüência e, para Lévi-Strauss, esta característica cumpre uma função própria no mito: tornar manifesta sua estrutura. É a estrutura sincrônico-diacrônica, característica do mito, que possibilita a ordenação de seus elementos em sequiências. As sequiências diacrônicas devem ser lidas sincronicamente. $\mathrm{O}$ desenvolvimento do mito é como em espiral, até o esgotamento do impulso intelectual que lhe originou. Em oposição à estrutura descontínua, o crescimento do mito é contínuo.

${ }^{5}$ Segundo o dicionário Aurélio: 1- Ato de aspirar; absorção. 2- Desejo ardente. 3- Pronunciação gutural de certas letras. 
Realizados estes apontamentos sobre o mito, cabe discutirmos o título de nosso trabalho, o qual fora emprestado - de alguma forma - da tese de doutorado de Costa (1998). O termo "recontagem" assinala aqui o que dele foi extraído pela pesquisadora, a saber, seu duplo sentido: por um lado, o termo marca a "repetição"6 de uma narração e, por outro, uma conta que é refeita.

O caráter duplo expresso pelo termo recontagem justifica nosso interesse pelo mito, desde que a criança, na recontagem de uma história, é posta em cena na sua fala e, a partir deste efeito, há algo de sua história e conta própria que, pela linguagem, promove uma versão outra de uma história que lhe chega pelo Outro.

A recontagem implica nesta duplicação, num desdobramento que produz equivalências, e sua criação se apóia não só no "não saber" da criança acerca da relação sexual como, especialmente, no engano mútuo determinado pela relação mãe- criança ${ }^{7}$, esta via faz que o imaginário (a ficção) seja tomado como real. Em sua conta a criança se conta duas vezes, desde que se situa não só como aquela que conta como naquilo que é contado, fato que aponta não para um erro de enunciação mas sim para "o germe de todo modelo enunciativo" (Costa, op.cit: 90).

Não há total liberdade nestas criações, já que dependem, como toda relação construída no âmbito humano,

"de um determinado encontro da história individual com as construções coletivas, responsáveis pelo registro onde se inscrevem mãe e criança” (Costa, op.cit:63).

Para a autora, esta versão é sinônimo de novela - na perspectiva freudiana, e de mito individual - no viés lacaniano.

Jacques Lacan (1995 [1957]) retorna mais uma vez em nossa fala, para citarmos algo de valioso, localizado no seminário da relação de objeto: “A verdade tem uma estrutura (...) de ficção” (op.cit, pág.259). No desenvolvimento do autor para chegar a esta conclusão, o mesmo partiu da constatação de que "O que se chama um mito, seja ele religioso ou folclórico, em qualquer etapa de seu legado que se o considere, apresenta-se como uma narrativa” (op.cit, pág.258). Antecedeu sua conclusão reflexões oriundas "do problema suscitado pelo fato de que o mito tem, no conjunto, um caráter de ficção” (op.cit, pág.258).

Segundo Lacan (1995 [1957]),

"esta ficção apresenta uma estabilidade que não a torna de modo algum maleável às modificações que lhe podem ser trazidas, ou, mais exatamente, que implica que toda modificação implica por sua vez, por essa razão, uma outra, sugerindo invariavelmente a noção de estrutura. Por outro lado, essa ficção mantém uma relação singular com alguma coisa que está sempre implicada por

\footnotetext{
${ }^{6}$ Repetição "reformulada", como discutido em momento anterior neste trabalho (págs. 1 e 2).

7 "Engano mútuo" no sentido de tratar-se de "uma mentira verdadeira organizada pela relação mãecriança” (Costa, op.cit:63), na qual tanto uma como a outra participam da criação do "corpo de ficção", isto é, de um corpo que substitui o corpo real da criança; este "corpo de ficção" é tido como a primeira ficção construída enquanto vivência individual. A criança participa por via da construção de teorias sexuais infantis e a mãe também participa da criação deste "corpo de ficção", na medida em que, num primeiro momento, ela precisa tomar o corpo da criança como próprio.
} 
trás dela, e da qual ela porta, realmente, a mensagem formalmente indicada, a saber, a verdade" (op.cit, pág. 258). Assim, temos a verdade como algo indissociável do mito.

Este psicanalista acrescenta:

"O mais adequado é dizer que a espécie de molde oferecido pela categoria mítica é um certo tipo de verdade na qual, por nos limitarmos ao que é nosso campo e nossa experiência, não podemos deixar de ver que se trata de uma relação do homem - mas com quê? (...) Cabe a nós apenas perceber que se trata de temas da vida e da morte, da existência e da não existência, do nascimento, em especial, isto é, da aparição daquilo que ainda não existe. Trata-se, pois, de temas ligados, por um lado, à existência do próprio sujeito e aos horizontes que sua experiência lhe traz, por outro lado, ao fato de que ele é o sujeito de um sexo, do seu sexo natural. Ai está o que nossa experiência nos mostra que a atividade mítica se emprega na criança” (Lacan, op.cit: pág.259).

Lacan (1992 [1970]) comenta, em um outro seminário:

"Fez-se agora do mito um ramo da lingüística. Quero dizer que o que de mais sério que se disse sobre o mito foi a partir da lingüística” (op.cit, pág. 103)

recomenda a seu auditório que se reporte ao texto de Lévi-Strauss com o qual trabalhamos no início de nossa fala. $\mathrm{O}$ autor se coloca como enunciando, neste momento de seu seminário, o mesmo que Lévi-Strauss em "A estrutura dos mitos"; e afirma: "digo que a verdade só se sustenta em um semi-dizer" (Lacan, op.cit: pág.103).

Foi ponderado por Lacan, pouco antes da afirmação destacada anteriormente:

"Não se vê porque a verdade seria sempre forçosamente benéfica. Só com o diabo no corpo é que se pode imaginar semelhante coisa, quando tudo demonstra o contrário” (op.cit, pág.99).

Segue sua síntese:

"o semi-dizer é a lei interna de toda espécie de enunciação da verdade, e o que melhor a encarna é o mito” (op.cit, pág. 103).

Jacques Lacan (1992 [1970]) declara que:

"Pode-se falar muita besteira em torno do mito, porque ele é justamente o campo da besteirada. E a besteirada (...) é a verdade. São idênticas” (op.cit, pág.104)

destaca que o mito de Édipo, da maneira como Freud fez funcionar, provoca a zombaria dos mitógrafos para, adiante, propor que saquemos "alguma coisinha do que corresponde ao mito de Édipo em Freud" (op.cit, pág.104). Lacan pontua que, tal como nos é contado por Freud, o complexo de Édipo não é tratado como um mito, desde que há uma subtração do trágico na versão freudiana da historieta de Sófocles.

O autor destaca como importante o fato de que "Édipo foi admitido junto a Jocasta porque tinha triunfado em uma prova de verdade" (Lacan,1992 [1970]:109). Assim, este psicanalista volta ao enigma da esfinge, não sem antes frisar que "se Édipo acaba tão mal (...), é porque ele quis absolutamente saber a verdade” (1969 [1970]: 109). Pôr este friso 
tem a função de marcar que, em uma abordagem séria da referência freudiana, há a impossibilidade de não se fazer intervir a dimensão da verdade.

Cabe, por fim, trazer a pontuação de Tavares (1998), numa reflexão acerca das histórias infantis:

"O fascínio que provocam certas historinhas reside em que elas colocam em cena, através do imaginário, significantes numa posição tal que lhes permitem articular algum saber sobre o que é a vida, a morte, o amor.. Um saber da mesma natureza que o que rege a vida dos adultos. Ou seja, ordenar com uma fórmula discursiva o que não pode ser transmitido na definição da verdade" (op.cit, pág.105).

Agrupados estes fragmentos introdutórios, revelamos que o mito - como tratado pelos autores que trouxemos - toma importância em nossa pesquisa, já que supomos encontrar aí um valioso instrumental para pensarmos o mito na história de uma criança. Mas ainda estamos no começo e, obviamente, resta muito trabalho.

\section{BIBLIOGRAFIA}

CALVINO, I. (1997). A combinatória e o Mito na arte da Narrativa. In: Atualidade do mito. São Paulo: Livraria Duas Cidades, pp.75-80.

COSTA, A.M.M. da (1998). A ficção do si mesmo: interpretação e ato em psicanálise. Rio de Janeiro: Companhia de Freud.

De LEMOS, C. T. G. (2002). Sobre o estatuto lingǘstico e discursivo da narrativa na fala da criança. In: Lingüística 13, pp.23-60.

FREUD, S. (1988 [1908]). Escritores criativos e devaneios. In: Obras psicológicas completas de Sigmund Freud, IX. Rio de Janeiro: Imago.

LÉVI-STRAUSS, C. (1995 [1958]). La Estructura de Los Mitos. In: Antropología estructural: Paidos. Barcelona, pp.229- 252.

LACAN, J. (1995 [1957]). O seminário, livro 4: a relação de objeto. Rio de Janeiro: Jorge Zahar Ed. (1992 [1970]). O seminário, livro 17: o avesso da psicanálise. Rio de Janeiro: Jorge Zahar Ed.

TAVARES, E. (1998). No reino dos pequeninos. In: Revista da Associação Psicanalítica de Porto Alegre APPOA - Ano VIII- Número 15 - novembro de 1998. 